\title{
In-Situ Cross-Sectional Observation of the Surface Phenomena of Materials
}

\author{
K. Sasaki, ${ }^{*}$ M. Hattori, ${ }^{*}$ S. Arai, ${ }^{* *}$ K. Kuroda*, and N. Tanaka** \\ * Department of Quantum Engineering, Nagoya University, Nagoya, Japan, 464-8603 \\ ** Ecotpia Science Institute, Nagoya University, Nagoya, Japan, 464-8603
}

In-situ heating transmission electron microscopy (TEM) experiments in the environmental cell have been tried by many researchers [1]. However, heating of the specimen of $3 \mathrm{~mm}$ in diameter causes severe drift during observation, which degrades the special resolution of the microscope. The heating holder using a wire heating filament has been developed by Kamino and Saka [2]. Although, the shape of the specimen was limited to powders, an atomic resolution at very high temperature has been obtained. The modified Kamino-Saka holder with the gas injection nozzle [3] allows the environmental heating experiment of the powder specimen in a gas environment at high temperatures. There is the strong demand of the cross-sectional observation of the specimen which preserves the microstructure of the material. We have employed the focused ion beam (FIB)-micro sampling technique [4] to prepare the specimen suitable for the in-situ environmental heating experiment using Kamino-Saka holder. The sublimation process of $\mathrm{Cu}$ and the surface partial melting of Al have been observed.

The FIB fabricated thin plate-like specimen was picked up by a micro-sampling needle. The heating filament was fixed onto the U-shaped $\mathrm{Cu}$ plate using spot welding, which we named the filament cassette. The filament cassette which can be fixed to the electrodes of the modified Kamino-Saka holder has been fixed to the FIB dedicated TEM specimen holder (Enomoto A\&V FIB Holder) first. Then the specimen holder was tilted 90 degree and the filament cassette was placed vertically keeping the filament upward in the FIB. Then the micro-sampled specimen was fixed onto the heating wire of the filament cassette using ion beam assisted $\mathrm{W}$ deposition. The specimen holder was moved to the CVD coating apparatus (Enomoto A\&V HC-1030) and then whole the surface of the specimen was coated by the plasma-polymerized film of $\mathrm{CH}_{4}$ and $\mathrm{C}_{2} \mathrm{H}_{2}$. After the coating, the specimen holder was moved back to FIB, and then a part of the film along the edge of the specimen was removed, which corresponded to the original surface of the specimen, to expose to the vacuum and/or environment. The prepared filament cassette with the specimen was fix onto the electrodes of the Kamino-Saka holder using screws and then the U-shape stem of the filament cassette was cut to separate the stem into two electrodes for both side of the electrodes of the holder. TEM observation has been performed in a JEOL JEM-1000K RS at an accelerating voltage of $1 \mathrm{MV}$.

The surface of standard electrode quality $\mathrm{Cu}(99.96 \%)$ was observed. Fig. 1(a) shows the asprepared specimen. The surface of the specimen on both side and the edge was coated by the plasma-polymerized film with the thickness of about 500nm except the central FIB removed part. The natural surface oxide layer sustained up to $980^{\circ} \mathrm{C}$. At $980^{\circ} \mathrm{C}$, as shown in Fig. 1(b) after the part of the oxide layer was broken, the rapid sublimation of $\mathrm{Cu}$ initiated the growth of the cavity between the plasma-polymerized film and $\mathrm{Cu}$. As the result of cavity expansion, whole the thin membrane of $\mathrm{Cu}$ has been sublimated as shown in Fig. 1(c)..

The wedge shape pure Al specimen completely coated by the plasma-polymerized film was observed at around melting temperature. Figure 2 shows partial melting from the edge of the 
specimen. The broken lines in the figures indicate the interface between the $\mathrm{Al}$ and the surface coated plasma-polymerized film. The position of solid-liquid interfaces were indicated by the gray and white triangles for both side of the figures. It was found that the position of sold-liquid interface could be controlled reproducibly as a function of heating current as shown in Fig. 2(a), (b) and (c). The position of solid-liquid interface of wedge shape specimen can be estimated using thermodynamics [5]. If the piece of the FIB fabricated wedge shaped material is fixed to the observing area of the TEM specimen, the direct measurement of the local area temperature on the TEM specimen could be possible.

The cross-sectional view of the sublimation process of $\mathrm{Cu}$ and the surface partial melting of Al have been observed. This method can be applicable any kind of material. Partial melting of wedge shaped Al suggested the possibility of local area temperature measurement of the TEM specimen.

\section{References}

[1] E.P. Butler and K.F. Hale, Dynamic Experiments in the Electron Microscope, ed. by A.M. Glauert, Practical Methods in Electron Microscopy Vol. 9, Elsiver/North-Holland, Amsterdam, 1981.

[2] T. Kamino and H. Saka, Microscopy Microanalysis Mircrostructure, 4 (1993) 127-135.

[3] T. Kamino, T. Yaguchi, M. Konno, A. Watabe, Y. Nagagakubo, Journal of Electron Microscopy 55 (2006) 245-252

[3] T. Yaguchi, R. Urao, T. Kamino, T. Ohnishi, T. Hashimoto, K. umemura, S. Tanimatsu, Mat. Res. Symp. Proc. 636, (2001) D9.35.1-6J.I.

[4] S. Tateno, R. Sinmyo, K. Hirose, H. Nishioka. Rev. Sci. Instrum. 80, (2009) 013901-1-4

[5] Y. Senda, K. Sasaki H. Saka, Phil. Mag. 84. (2004) 2635-2649
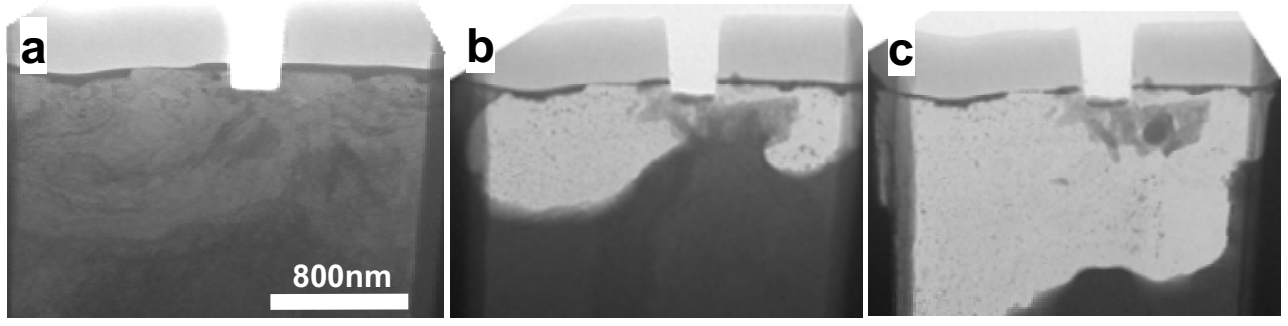

FIG. 1. The cross-sectional view of the surface of $\mathrm{Cu}$ specimen (a) before heating, (b) during cavity formation at $980^{\circ} \mathrm{C}$ and (c) after heating .

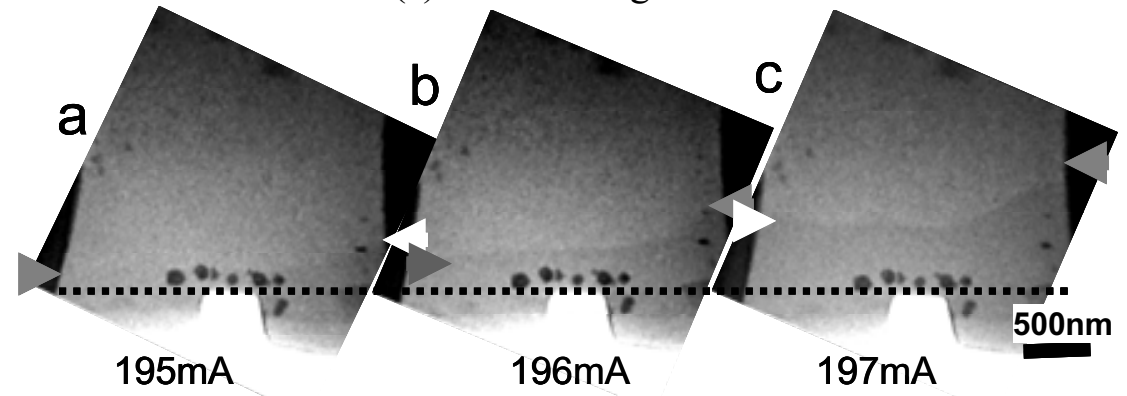

FIG. 2. Partial melting of the wedge shaped Al. The position of the solid-liquid interface can be controlled by changing the heating current to (a) $195 \mathrm{~mA}$, (b) $196 \mathrm{~mA}$ and (c) $197 \mathrm{~mA}$, reproducibly. 